\title{
Papaya Dieback in Malaysia: A Step Towards A New Insight of Disease Resistance
}

\author{
Hamidun Bunawan *, Syarul Nataqain Baharum \\ Institute of Systems Biology, University of Kebangsaan Malaysia, 43600 Bangi, Selangor, Malaysia \\ ${ }^{*}$ Corresponding author: Hamidun Bunawan, Institute of Systems Biology, University of Kebangsaan Malaysia, 43600 Bangi, Selangor, Malaysia. Tel: +60- \\ 389214550, Fax:+60-389214550, E-mail: hamidun.bunawan@bristol.ac.uk
}

Received: January 23, 2015; Revised: September 26, 2015; Accepted: November 11, 2015

A draft genome of Erwinia mallotivora BT-Mardi (1), the causal pathogen of papaya dieback infection in Peninsular Malaysia, has significant potential to overcome and reduce the effect of this vulnerable crop (2). The authors found that the draft genome sequence is approximately $4824 \mathrm{Kbp}$ and the $\mathrm{G}+\mathrm{C}$ content of the genome was $52-54 \%$, which is very similar to the reference genomes of other Erwinia species. They concluded that the draft genome would be useful for understanding host-pathogen interaction and determining the mechanism of infection of the disease. In addition to this, we believe that there are some further directions that should be considered in the future.

Firstly, the comprehensive analysis of pathogenicity genes in E. mallotivora, which would enable the comparison of genes important in pathogenicity between species in the genus Erwinia, and highlight any differences. These include the most important and well-studied pathogenicity system in gram negative bacteria: the Type III Secretion (TTSS). Investigation of genes important in the pathogenesis of E. mallotivo$r a$ will decipher the function of these genes and unravel the complex interaction of the bacteria and host, and this will enable the understanding of their capabilities to enter plant cells, overcome host resistance and induce disease. This in-depth understanding will potentially allow the identification and application of new sources of biocontrol for this disease.

Secondly, the elucidation and identification of the potential pathogen-inducible and defence-related genes in papaya. The papaya genome is available onlineto enable the identification of the putative immunity related genes (IRG) and it will be greatly useful for revealing the blueprint of host genes under pathogen stress. Wee et al. (3) reported the expression analysis for four possible defence related genes in the E. mallotivara host (zinc finger protein, leucine rich protein, aquaporin and peroxidase), in order to understand the defence mechanisms in papaya. This information will be valuable for strategies in generating host resistance and understanding host-pathogen interaction.

Thirdly, the discovery of papaya microRNAs (miRNAs) is also important. Previous studies have shown that miRNAs could act in wide range of biological processes as well as in the plant's defence system towards biotic and abiotic stresses. Therefore, profiling and functional analysis of miRNAs would be important to generate novel possibilities in improving resistance to dieback. The high potential application of miRNAs in the host defence mechanism indicates that they should be used or manipulated to confer pathogen resistance in papaya.

Finally, the development of resistant plants using a genetic engineering approach is also an important tool in the control of papaya dieback disease. Currently, there is no chemical control treatment available and no resistant papaya varieties offered in order to overcome this severe disease, and generating resistant plants using a biotechnology approach could be the solution. The strategy of disruption of bacterial virulence factors, improvement of plant defence responses and the expression of antimicrobial proteins of non-plant origin could be applied in papaya to confer resistance.

The draft genome of E. mallotivora BT Mardi is the first step and the initial key to the understanding of the host-microbe interaction and mechanism of infection of this severe disease. This could be fundamental for 
plant pathologists, molecular biologists and botanists in Malaysia - it could help them to focus on the ultimate goal of control of papaya dieback disease.

\section{Acknowledgements}

The authors would like to thank Kathryn Ford, University of Bristol for her editorial comments on this letter.

\section{Conflict of interest}

The author declares there is no conflict of interest regarding the publication of this paper.

\section{References}

1. Redzuan RA, Abu Bakar N, Rozano L, Badrun R, Mat Amin N, MohdRaih MF. Draft genome sequence of Erwinia mallotivora BT-MARDI, causative agent of papaya dieback disease. Genome Announc. 2014;2(3):e00375-14. DOI: 10.1128/genomeA.00375-14.

2. Mat Amin N, Bunawan H, Redzuan RA, Jaganath IBS. Erwinia mallotivora sp., a New Pathogen of Papaya (Carica papaya) in Peninsular Malaysia. Int J Mol Sci. 2011;12(1):39-45. DOI: 10.3390/ijms12010039

3. Wee CY, Muhammad Hanam H, Mohd Waznul Adly MZ, Khairun HN. Expression of defense-related genes in papaya seedling infected with Erwinia mallotivora using real-time PCR. J Trop Agric Fd Sc. 2014;42(1):73-82. 